\title{
Perilimbal vascular anomaly associated with ipsilateral en coup de sabre morphoea
}

\author{
P TAYLOR' AND E M TALBOT ${ }^{2}$ \\ From the 'Department of Ophthalmology, Royal Preston Hospital, Preston; and \\ ${ }^{2}$ St Paul's Eye Hospital, Liverpool
}

SUMmARY An unusual case of red eye is described where preceding ipsilateral en coup de sabre morphoea is associated. The suggested aetiology of morphoea and its ocular associations are described.

\section{Case report}

A 58-year-old woman was concerned about her bloodshot left eye and the blueness of the upper lid (Fig. 1). The bloodshot eye had worsened during the last two years, but there were no other significant symptoms, and a subjective bruit was denied.

She had suffered from migraine since her youth. She was investigated by a neurologist in 1972 after a severe bout of migraine. Her history suggested a right sided subarachnoid haemorrhage, but this was not confirmed. In 1974 and 1978 stiffness in her joints and back pain were investigated. On examination there was no pulsatile proptosis, no cranial nerve defect, no carotid bruit, and no conjunctival chemosis. Visual acuity was $6 / 5$ in the right eye, and 6/6 in the left eye. Slit lamp examination and fundus examination were normal as was applanation tonometry. However, there was an atrophic area of skin on her forehead (Fig. 2). This had the characteristic appearance of classical morphoea with contraction and firmness of the area, alopecia, and ivory skin with areas of telangiectasis and hyperpigmentation. The position of this morphoea was frontoparietal, and was recognised as sclerodermia en coup de sabre (a sabre blow).

The lesion began as an inflamed area and progressed to become atrophic and fibrotic over the 18 years prior to her eye complaint. This previously normal skin had never had a significant direct trauma or burn, though two years prior to the development of acute phase morphoea there was a car mirror injury to the posterior parietal scalp on the same side.

Correspondence to Dr E M Talbot, St Paul's Eyc Hospital, Old Hall Street, Liverpool L3 9PF.
Investigations made prior to dermatological diagnosis included: conjunctival culture and scrape; full blood count and erythrocyte sedimentation rate; chest $x$ ray and electrocardiogram; $x$-rays of skull, orbits, and optic foramina; thyroid function; technetium-99 scan; encephalogram; lumbar puncture; Wassermann reaction; and examination of sacroiliac joints. All were negative. The skull $x$-ray showed ipsilateral hyperostosis frontalis.

As her only complaint was cosmetic (there were no headaches, neurological, or other ophthalmological conditions), invasive investigations such as biopsy, venography, and carotid angiography were thought not to be justified.

Argon laser treatment to occlude limbal vessels was attempted, but the patient was intolerant. Cautery or cryotherapy to proximal feeding and draining vessels may be tried later. There is no recommended treatment for local morphoea. At follow-up one year later this woman was fit and well with no further eye change. However, she believes that the same signs of tightness and atrophy on her forehead are starting to appear on the upper left cheek. This may be a progression of the en coup de sabre.

\section{Discussion}

Morphoea is a localised form of scleroderma and usually has no systemic effect. It regresses and has a benign prognosis. En coup de sabre is a linear groove that usually starts in the frontoparietal region but may extend down to the cheek, nose, lip, or chin. It has many associations, particularly ocular.' The cause of morphoea is unknown, but previous trauma is suspected. It has been suggested that this trauma 


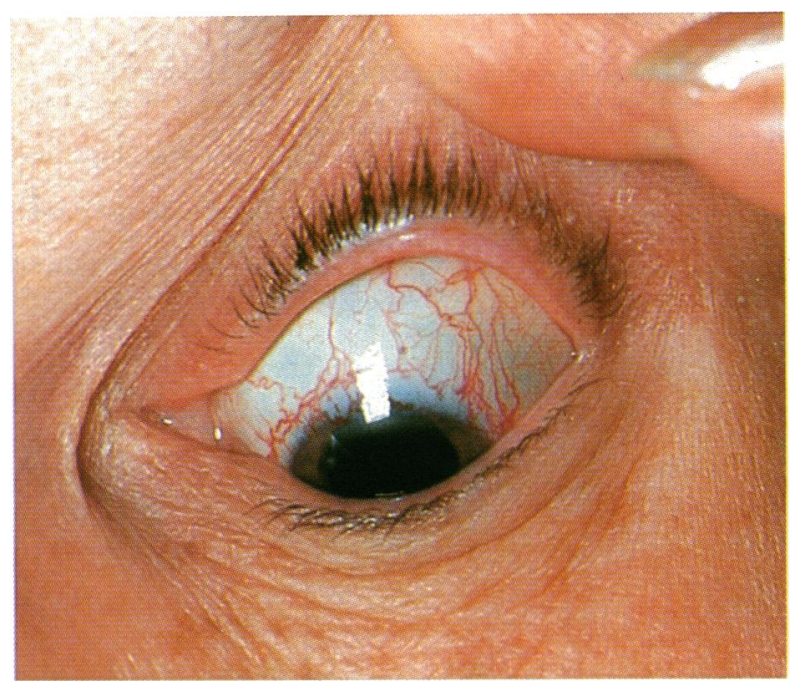

Fig. 1 Perilimbal vascular anomaly.
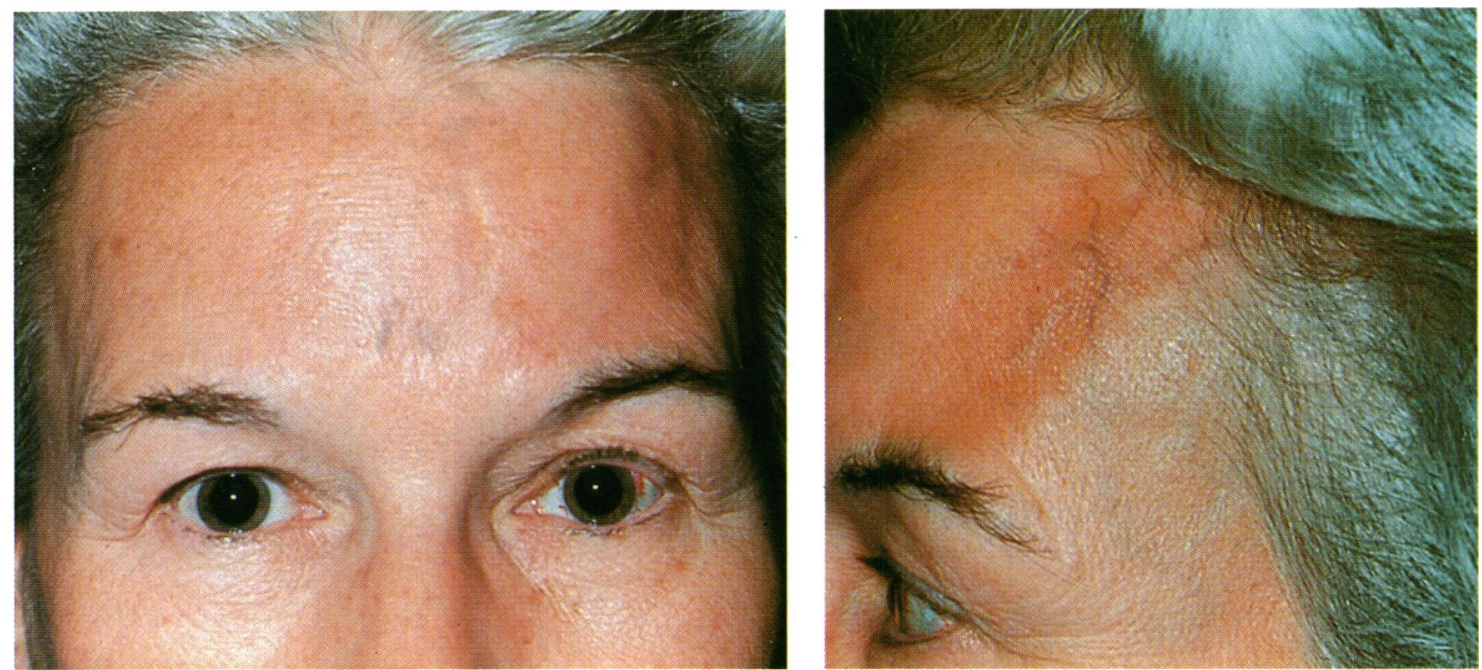

Fig. 2 Left frontoparietal en coup de sabre morphoea with ipsilateral perilimbal vascular anomaly.

may induce an autoimmune reaction. Scleroderma is seen in the graft versus host syndrome. Panayai ${ }^{2}$ claimed that a cell mediated immune reaction caused chronic tissue damage. The pathology of morphoea (dermis) supports this. In the acute phase there is swelling and a chronic inflammatory reaction. Lymphocytes, plasma cells, and monocytes are prominent, and there is atrophy of the skin appendages. It seems that wherever there is an area of morphoea it is possible that the underlying area may have an associated abnormality such as skin or bone change and, in the case of en coup de sabre, ocular abnormalities. Saad and $\mathrm{Khoo}^{3}$ described complete cleft lip and palate that developed in association with morphoea of the face in a previously outwardly and radiologically normal child.

The most commonly associated ocular conditions include: skin atrophy and loss of sensation; sector iris atrophy and heterochromia; raised intraocular pressure, and external ocular muscle paresis; and ptosis. Others reported include: lid lash problems and entropion or ectropion (Nancarrow et $a^{4}$ discussed management of scleroderma of the eyelids causing ectropion with the use of skin grafts); decreased corneal sensation and corneal dystrophy; lens opacity; vitreal haemorrhage; choroiditis; optic nerve atrophy; myositis; skull and EEG changes. Follow-up should be directed towards monitoring 
and controlling previous abnormalities and notice taken of the possible development of further associations. In conclusion it is believed that the perilimbal vascular anomaly and the preceding morphoea on the same side are directly related.

We thank the Preston and Chorley Rescarch Fund for funding the coloured photographs, Mr SI Davidson for his constructive criticism, and Miss E A Wreyford for typing the manuscript.

\section{References}

1 Perrot H, Durand L, Thivolet J, Millon M, Ortonne JP. Sclérodermic en coup de sabre et glaucome chronique homo-lateral. Ann Dermatol Venereol 1977; 104: 381-6.

2 Panayai GS. The immunopathology of connective tissue disorders. Medicine (Baltimore) 1979; 14: 686-9.

3 Saad MN, Khoo CTK. Localized scleroderma of the premaxilla and upper lip. Br J Plast Surg 1980; 33: 245-50.

4 Nancarrow JD, Salah MAJ. A rare case of severe bilateral cctropion from scleroderma. Plast Reconstr Surg 1981; 67: 352-4. 